\title{
Modal analysis of a multiple structure
}

\author{
Stanko Čolak ${ }^{1, *}$ and Ante Džolan ${ }^{1}$ \\ ${ }^{1}$ University of Mostar, Matice Hrvaske Str. Bb, 88000, Mostar, Bosnia and Herzegovina
}

\begin{abstract}
The aim of the work was to carry out a modal analysis of a multiple structure. Own forms of oscillation of the structure for five tones were obtained through the vector iteration process and were presented in table and graphic form. Using the different methods (Time history, SRSS and CQC), a calculation of the displacements was performed. Theoretically, all three methods are described and the results of the calculation for each of them are obtained. A comparison of the results, for the three methods in a given time interval, is graphically shown. Also, the results are compared which are all the same in all three methods. The modal seismic analysis of Spectral Theory was also performed. It can be concluded that by comparing the method of Time history and Spectral theory their results correspond to the maximum modal displacement.
\end{abstract}

\section{Introduction}

In this paper, the procedure of modal analyzes of five-storey structure is proved.

The second point briefly describes the modal analysis theoretically, and then defines the design of structure and the data required to perform calculations of the modal structural analysis of structure.

The third point briefly describes the vector iteration process that produces its own forms of oscillation of the structure for all 5 tones and finally presents own forms of oscillations of the structure in a table and graphically.

In the fourth point he proved the calculation of the shift according to the methods Time History, SRSS and CQC. The methods Time History, SRSS and CQC were first described theoretically, after which, after the proven calculations and the results obtained for all three methods, a comparison of the displacements for all three methods in a given time interval and the results are commented.

In the fifth point, the calculation of the modal seismic analyzes of the spectral theories for the first mode is proved and the results of the time-dependent shift are graphically presented. Finally, a comparison of the maximum modal displacement obtained with respect to Time History and Spectral Theory is presented graphically.

A conclusion is drawn at the end of this paper.

\footnotetext{
*Corresponding author: stanko.colak@gf.sum.ba
} 


\section{Geometry and construction data}

Modal analysis is a dynamic analysis of linear systems with $\mathrm{N}$ degrees of freedom, which is based on the method of developing in its own forms or tones. This method is applicable if the time dependence of the excitation force of all masses is the same or relatively the same, which in the case of earthquake load satisfies the required condition.

The solution to the problem is to solve the matrix differential equation:

$$
[m] \cdot\{\ddot{u}\}+[c] \cdot\{\dot{u}\}+[k] \cdot\{u\}=\{p(t)\}
$$

The calculation of the modal analysis of a five-storey structure with the dimensions of columns $\mathrm{b} / \mathrm{h}=30 / 30 \mathrm{~cm}$ was carried out, the beams of the construction were observed as absolutely rigid in the direction of oscillations, the inter-storey height of the structure is 3.0 $\mathrm{m}$, the span of the beams is $6.0 \mathrm{~m}$, and the masses are concentrated in the level of interstorey structures (beams), respectively

$$
m_{1}=m_{2}=m_{3}=m_{4}=6 \text { tonnes, } m_{5}=3 \text { tonnes }
$$

The masses are numbered from the first to the fifth floor. The damping coefficient of the structure is $\xi=5$ and the acceleration of the substrate is $\mathrm{a}_{\mathrm{g}}=0.35 \mathrm{~g}$.

their text citation.
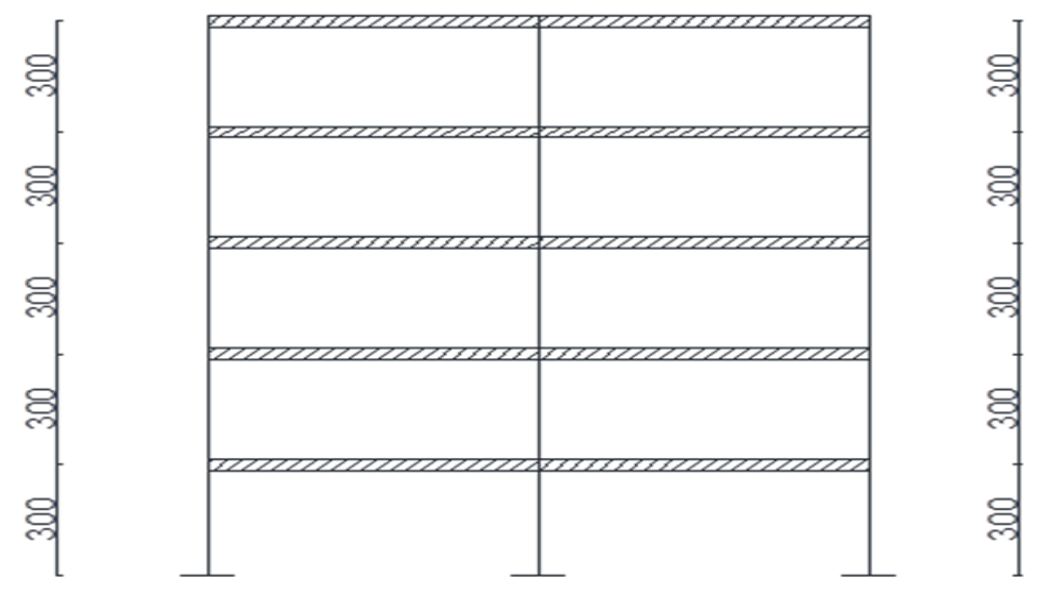

600 600

Fig. 1. Default five-story structure.

\section{Vector iteration to obtain its own forms of oscilation}

When calculating modal structural analysis, we first need to determine the bending moment diagram of the unit masses of each floor. By multiplying these diagrams, we get members of a flexibility matrix that looks like this:

$$
D=\frac{1}{E I}\left[\begin{array}{lllll}
0,75 & 0,75 & 0,75 & 0,75 & 0,75 \\
0,75 & 1,50 & 1,50 & 1,50 & 1,50 \\
0,75 & 1,50 & 2,25 & 2,25 & 2,25 \\
0,75 & 1,50 & 2,25 & 2,25 & 2,25 \\
0,75 & 1,50 & 2,25 & 2,25 & 2,25
\end{array}\right]
$$


For the purposes of calculating modal structural analysis, we also need a mass matrix:

$$
M=m\left[\begin{array}{lllll}
2 & 0 & 0 & 0 & 0 \\
0 & 2 & 0 & 0 & 0 \\
0 & 0 & 2 & 0 & 0 \\
0 & 0 & 0 & 2 & 0 \\
0 & 0 & 0 & 0 & 1
\end{array}\right], \quad m=3 \text { tonnes }
$$

Multiplying the mass matrix and the flexibility matrix, we obtain a dynamic mass matrix:

$$
\left[D_{M}\right]=D \cdot M=\frac{2,25}{E I} \cdot\left[\begin{array}{ccccc}
2 & 2 & 2 & 2 & 1 \\
2 & 4 & 4 & 4 & 2 \\
2 & 4 & 6 & 6 & 3 \\
2 & 4 & 6 & 8 & 4 \\
2 & 4 & 6 & 8 & 5
\end{array}\right]
$$

Once we have determined the dynamic matrix of masses, we go into a vector iteration process to obtain our own oscillation forms

Table 1. Setting Word's margins.

\begin{tabular}{|c|c|c|c|c|c|}
\hline \multirow{2}{*}{ Mass } & \multicolumn{5}{|c|}{ Own forms } \\
\cline { 2 - 6 } & I tone & II tone & III tone & IV tone & V tone \\
\hline 1 & 1 & 1 & 1 & 1 & 1 \\
\hline 2 & 1.902 & 1.177 & 0 & -1.185 & -3.982 \\
\hline 3 & 2.618 & 0.383 & -0.996 & 0.41 & 2.479 \\
\hline 4 & 3.078 & -0.727 & 0 & 0.682 & -6.315 \\
\hline 5 & 3.236 & -1.237 & 0.996 & -1.193 & 2.941 \\
\hline
\end{tabular}

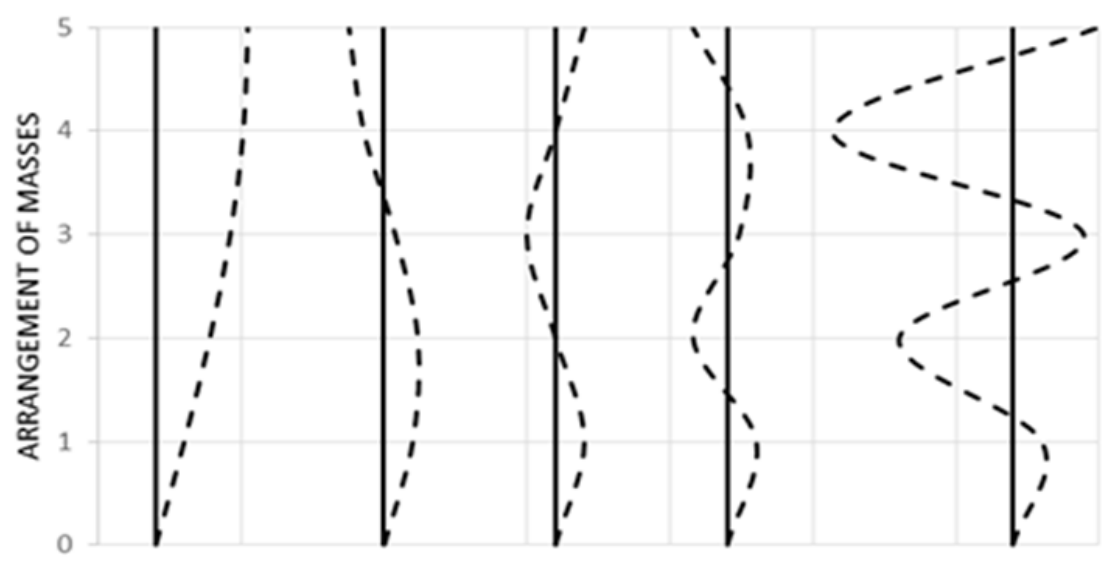

TONES (from left to right, from 1 to 5 )

Fig. 2. Own forms of oscillation.

\section{Displacement comparison over Time history, SRSS and CQC methods}

Time history represents the actual displacements of a given mass on the structure and depends on the relative displacement of mass in tone and number of modes: 


$$
\begin{aligned}
& u_{i}(t)=\sum_{j=1}^{n} a_{i j} \cdot x_{j}(t) \\
& u_{i}(t)=\sum_{j=1}^{n} a_{i j} \cdot x_{j}(t)
\end{aligned}
$$

$a_{i j} \rightarrow$ relative displacement of mass " $i$ " in tone " $j "$

$n \rightarrow$ number of modes

$i \rightarrow$ mark of mass

$j \rightarrow$ mark of mode

SRSS - the square root of the sum of squares - is a modal combination that squares each peak value of each shape. The root of the sum of the squares of these peaks gives a complete answer:

$$
u_{i, \max }=\sqrt{\sum_{j=1}^{n} u_{i j}^{2}}
$$

$u_{i, \max } \rightarrow$ displacement of mass " $\mathrm{i}$ " calculated by SRSS

$u_{I J} \rightarrow$ displacement of mass " $\mathrm{i}$ " in " $\mathrm{j}$ " tone

This modal combination assumes that the maximum modal values are statistically independent. As these are squares of values, each peak value becomes positive. In the case of structures where a large number of natural frequencies are almost identical, this assumption will not be valid and this modal combination will then not give satisfactory values for the overall response.

CQC - complete quadratic combination, is the product of the peak values of the $\mathrm{i}$-th and $\mathrm{n}$-th form and the correlation coefficient for the two forms. The correlation coefficient varies between values 0 and 1 and is equal to the unit value for $i=n$.

$$
U_{k, \max }=\sqrt{\sum_{i=1}^{n} \sum_{j=1}^{n} u_{k i} a_{i j} u_{k j}}
$$

$u_{i, \max } \rightarrow$ displacement of mass " $\mathrm{k}$ " calculated by CQC

$u_{k i}, u_{k j} \rightarrow$ displacement of mass " $\mathrm{k}$ " in " $\mathrm{i}$ ", respectively in " $j$ " tone 


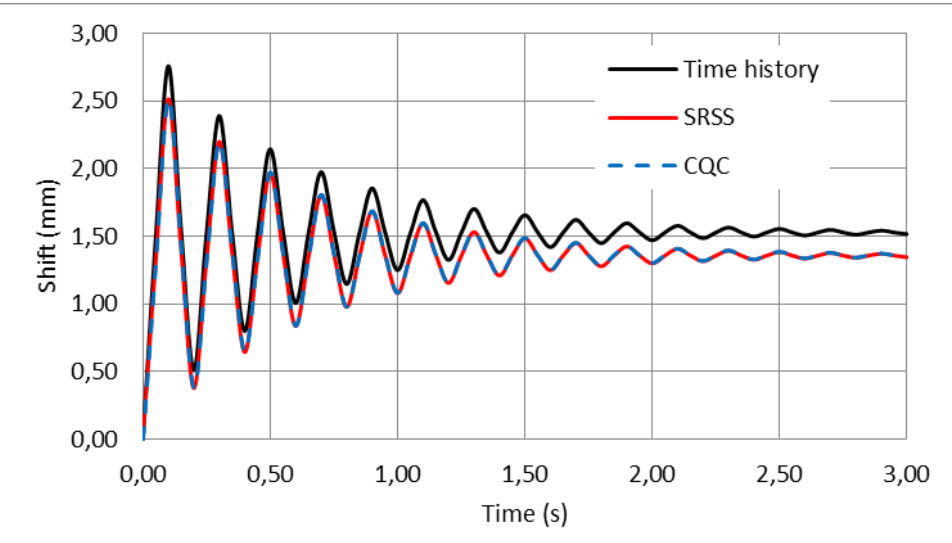

Fig. 3. Comparison of displacement of mass 1 by Time history, SRSS and CQC.

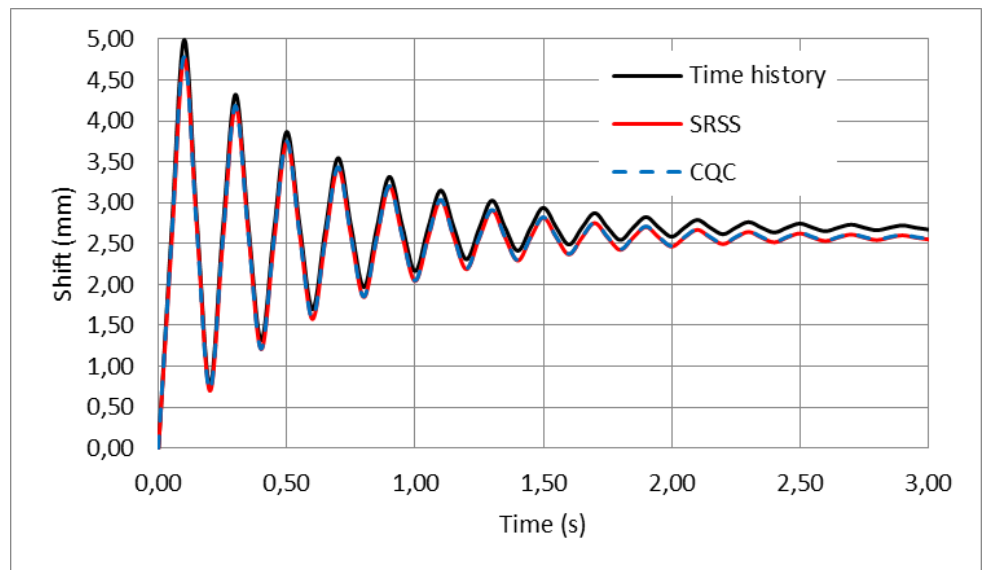

Fig. 4. Comparison of displacement of mass 2 by Time history, SRSS and CQC.

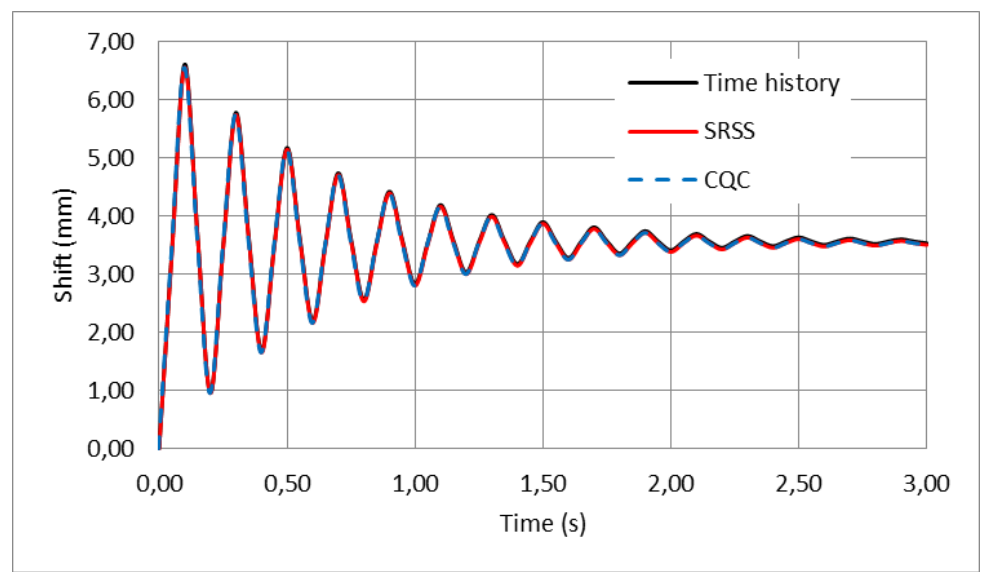

Fig. 5. Comparison of displacement of mass 3 by Time history, SRSS and CQC. 


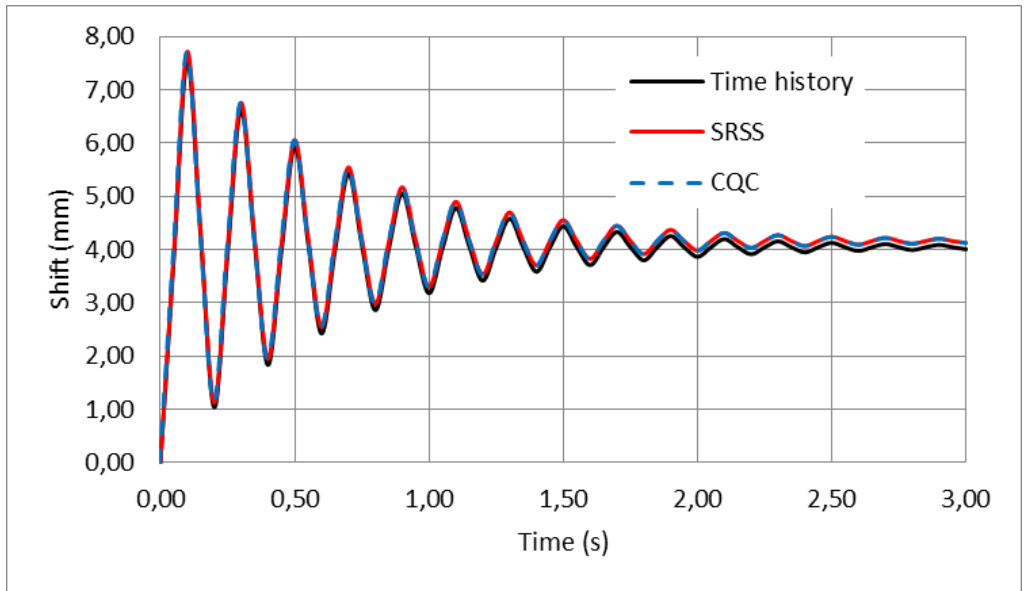

Fig. 6. Comparison of displacement of mass 4 by Time history, SRSS and CQC.

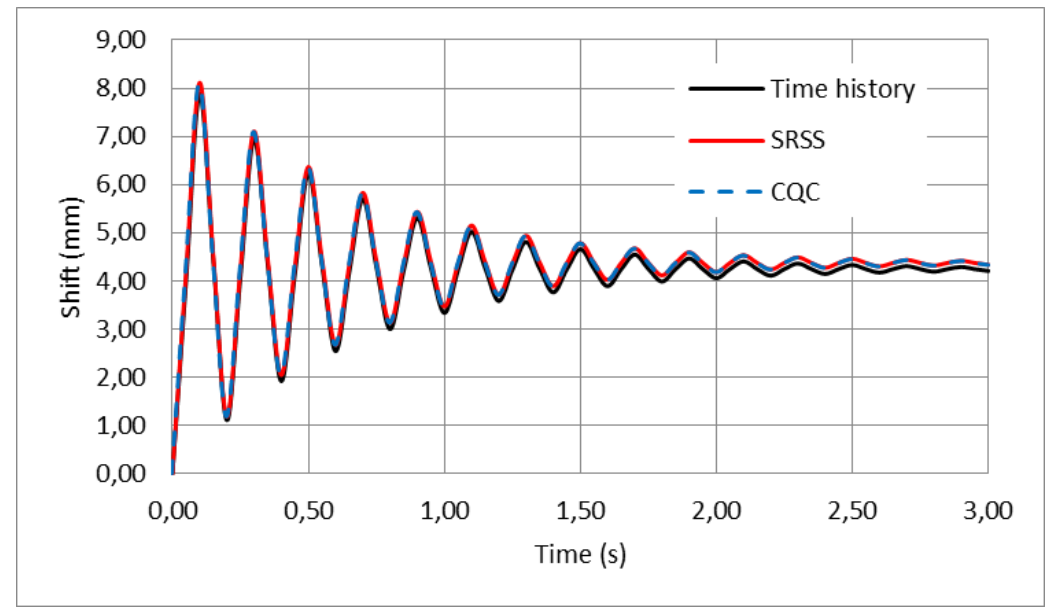

Fig. 7. Comparison of displacement of mass 5 by Time history, SRSS and CQC.

From the obtained results and figures we can see that the mass shifts according to Time history, SRSS and CQC are approximately equal, only there are small differences in mass 1 between Time history and the other two (SRSS and CQC) methods.

\section{Modal seismic analysis by spectral theory}

Modal seismic analysis by spectral theory was performed only for the first mode because the oscillation periods with the remaining tones are too small.

The calculation of the $1940 \mathrm{El}$ Centro earthquake displacement response spectrum, 5\% attenuation (Figure 8) was used and the results are given below. 


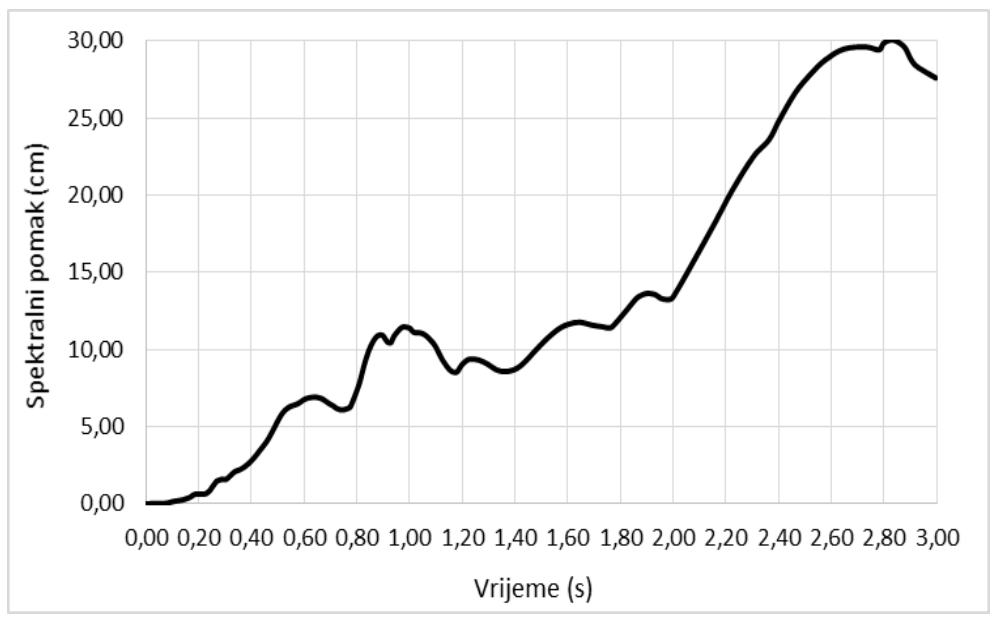

Fig. 8. Spectral Shift Diagram.

$$
T_{1}=\frac{2 \pi}{\omega_{1}}=\frac{2 \pi}{31,48}=0,2 \mathrm{~s} \rightarrow \text { for period of oscilation } T=0,2 \mathrm{~s} \text { the spectral }
$$

shift $B$ of $0,634 \mathrm{~cm}$ is obtained from the shift

response spectrum

$$
\begin{gathered}
\ddot{x}_{1}+2 \cdot \xi \cdot \omega_{1} \cdot \dot{x}_{1}+\omega_{1}^{2} \cdot x_{1}=0,39 \cdot a_{g} \rightarrow \bar{x}_{1}=0,39 \cdot 0,634 \\
\bar{x}_{1}=0,247 \mathrm{~cm}=2,47 \mathrm{~mm}
\end{gathered}
$$

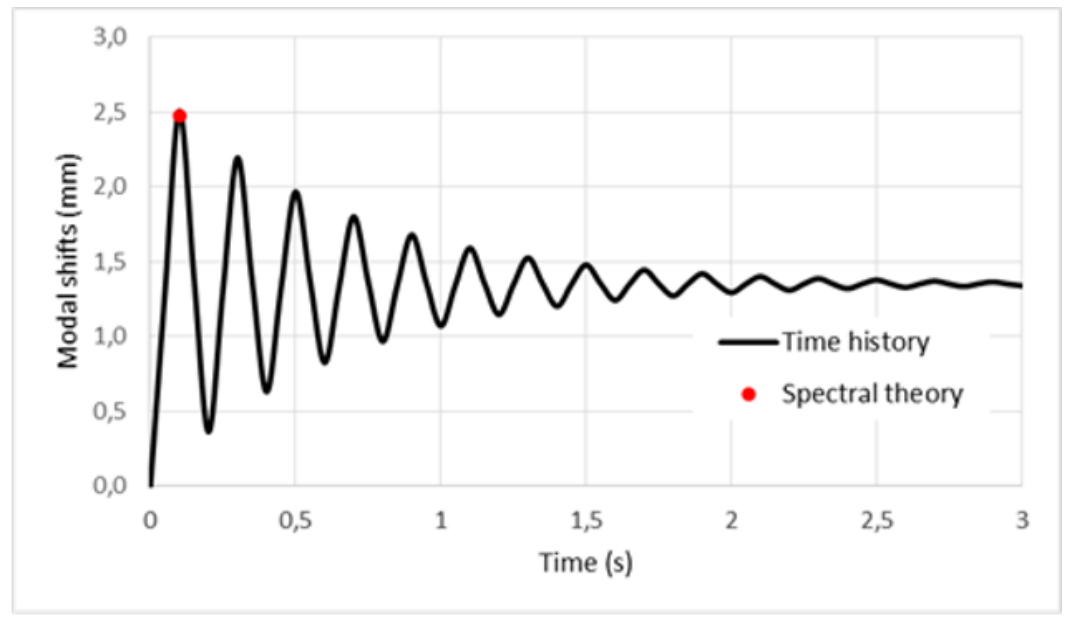

Fig. 9. Comparison of Time history and Spectral theory.

Figure 9 shows a good match between the maximum modal displacement obtained by Time history and Spectral theory.

\section{Conclusions}

The modal analysis results for the observed structure are fully in line with expectations. It can be seen that in its own forms of oscillation of the structure for the first tone, the 
displacement of each part is in the same direction, and as each tone increases, the number of changes in the direction of oscillation increases. At the fifth tone of oscillation, it can be seen that each subsequent mass changes the direction of oscillation.

After calculating the displacement according to Time history, SRSS and CQC methods, it can be seen that the results according to all three methods are approximately the same, only there are small differences in mass 1 between Time history and the remaining two (SRSS and CQC) methods.

Finally, the calculation of the modal seismic analysis by spectral theory was performed. This calculation shows a good match between the maximum modal displacement obtained by the Time history method and the Spectral theory.

\section{References}

1. T. Kalman, V. Sigmund, Tehnički vjesnik 14, 17-24 (2007)

2. A. Džolan, Skripta sa zadatcima iz kolegija Dinamika konstrukcija $i$ potresno inženjerstvo (Faculty of civil engineering Mostar, Mostar 2018)

3. S. Au, Operational Modal Analysis, Modeling, Bayesian Inference, Uncertainty Laws, Center for Engineering Dynamics and Institute for Risk and Uncertainty (University of Liverpool, UK, 2017) ISBN 978-981-10-4117-4, DOI 10.1007/978-981-10-4118-1

4. S. Čolak, A. Džolan, Modalna analiza višekatne konstrukcije, Zajednički temelji (Faculty of civil engineering Rijeka, Rijeka 2019) DOI: 256.26.56.25.545.5.45.4.5 